\title{
Development of a Highly Oriented Poly-biphenylenebisoxazole Fiber Obtained via a Precursor Polymer Spun From a Liquid Crystalline Aqueous Solution
}

\author{
By Masayuki ChoKaI, ${ }^{1,3}$ Dennis Wilbers, ${ }^{2}$ Bunsow NAGASAKA, ${ }^{1}$ Hiroaki KuWAHARA, ${ }^{1}$ \\ Ton de WEIJER, ${ }^{2}$ Enno KLOP, ${ }^{2}$ Teruaki HAYAKAWA, ${ }^{3}$ and Masa-aki KAKIMOTO ${ }^{3, *}$
}

A novel route for the production of the rigid rod fiber poly-2,2'-(p-phenylene)-6,6'-bibenzoxazole (biPBO) was investigated. This fiber was prepared via its precursor polymer poly(3,3'-dihydroxybenzidine terephthalamide), abbreviated as DHBTA. The dissolution behavior of the precursor polymer was tested in various solvents and it was found that basic aqueous solutions are suitable for spinning purposes. A highly concentrated solution $(15 \mathrm{wt} \%)$ of the precursor polymer in aqueous tetramethylammonium hydroxide (TMAH) shows liquid crystalline behavior. Oriented DHBTA fibers were produced by wet spinning of the precursor polymer from liquid crystalline TMAH solutions. The resulting yarn showed much higher orientation and considerably better mechanical properties than a yarn spun from an isotropic solution of the precursor polymer in $N$-methyl-2-pyrrolidone. Highly oriented biPBO fibers were obtained after heating the precursor yarn to temperatures up to $450^{\circ} \mathrm{C}$ in order to achieve ring closure. In conclusion, biPBO yarn with promising tensile properties was obtained by spinning from aqueous solutions instead of corrosive sulfuric acid, phosphoric acid or organic solvents.

KEY WORDS: biPBO Fiber / Lyotropic Liquid Crystalline / Aqueous Solution / Aromatic Polyhydroxyamide / Precursor / Ammonium Salt /

Aromatic polyamides, such as poly ( $p$-phenylene terephthalamide) (PPTA), are materials that can be shaped into various forms, such as fibers or pulp, for applications requiring excellent mechanical properties and heat resistance. High performance PPTA fibers are obtained from a lyotropic liquid crystalline solution of PPTA in sulfuric acid via a wet spinning process. ${ }^{1-4}$ Polybenzoxazole (PBO) fiber has superior mechanical properties in comparison to PPTA, especially in tensile modulus and strength. PBO fiber can be obtained from a lyotropic liquid crystalline solution of the polymer in polyphosphoric acid (PPA), also via a wet spinning process. ${ }^{5-8}$ The solvents employed in these spinning processes are corrosive acids. Therefore the spinning equipment has to be made from a special alloy to minimize corrosion problems. ${ }^{9}$ Recycling of these corrosive solvents may also present problems.

Other processes for the production of polybenzoxazole fibers have been proposed. It was reported that biPBO fibers can be prepared from aromatic polyhydroxyamide precursors in organic solvents. ${ }^{10}$ In this process the precursor fiber was spun directly from the reaction solution, and then the spun fiber was heated in order to form the biPBO structure via a ringclosure reaction. The poor solubility of the precursor polymer in organic solvents makes it difficult to prepare liquid crystalline solutions. Researchers at General Electric Co., Ltd. described a process for the production of thin films and fibers via extrusion of aqueous solutions of alkali metal salts of various aromatic polyhydroxyamides. ${ }^{11}$ However, a detailed description of the properties of the products formed was not given.

Lyotropic main-chain liquid crystal polymers are of technological importance since they can be spun from liquid crystalline solutions into high-strength high-modulus fibers. Achieving solubility and the formation of liquid crystalline phases of main-chain polymers in water or other common solvents would have some obvious processing advantages. Here we describe a novel process for the production of biPBO fiber from a lyotropic liquid crystalline solution of the polyhydroxyamide precursor poly(3,3'-dihydroxybenzidine terephthalamide), hereafter abbreviated as DHBTA. In this process biPBO yarn with promising tensile properties was obtained by spinning from aqueous solutions instead of corrosive sulfuric acid, phosphoric acid or organic solvents.

\section{EXPERIMENTAL}

\section{Materials}

3,3'-Dihydroxybenzidine, $N$-methyl-2-pyrrolidone (NMP), and calcium chloride were obtained from Wako Pure Chemical Industries Co., Ltd. Terephthaloyl chloride was obtained from Tokyo Kasei Kogyo Co., Ltd.

\section{Measurements}

Inherent viscosities were measured at a concentration of $0.5 \mathrm{~g} \mathrm{dL}^{-1}$ with a Ubbelohde type viscometer in concentrated

\footnotetext{
${ }^{1}$ Technology Innovation Center, Teijin Ltd., 2-1 Hinode-cho, Iwakuni 740-8511, Japan

${ }^{2}$ Teijin Aramid BV, Research Institute, P.O. Box 9600, 6800 TC Arnhem, the Netherlands

${ }^{3}$ Department of Organic \& Polymeric Materials, Tokyo Institute of Technology, 2-12-1, O-okayama, Meguro-ku, Tokyo 152-8550, Japan

*To whom correspondence should be addressed (Tel: +81-3-5734-2433, Fax: +81-3-5734-2875, E-mail: mkakimoto@o.cc.titech.ac.jp).
} 


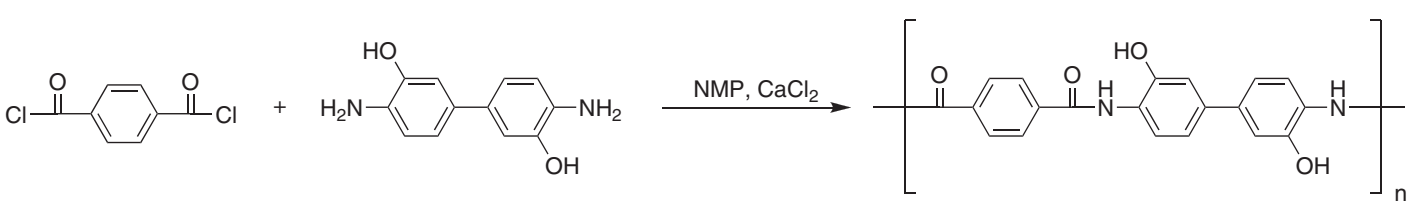

Scheme 1. Preparation of DHBTA in NMP in the presence of $\mathrm{CaCl}_{2}$.

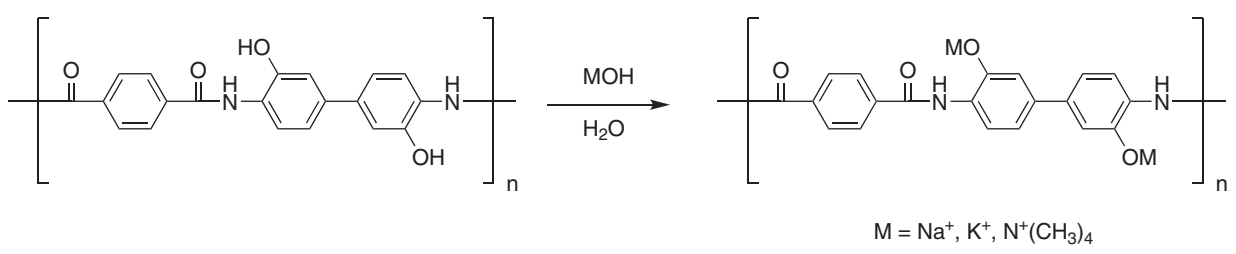

Scheme 2. Dissolution of DHBTA in basic aqueous solution

sulfuric acid at $30^{\circ} \mathrm{C}$. Thermogravimetric analysis (TGA) was performed at a heating ratio of $10^{\circ} \mathrm{C} / \mathrm{min}$ under $\mathrm{N}_{2}$ on a Seiko TG/DTA 6200. IR spectra were measured on a $\mathrm{KBr}$ pellet with a FT-IR SPECTRA TECH. IR-PLAN. Wide angle X-ray diffraction (WAX) measurements were carried out using $\mathrm{CuK}_{\alpha}$ radiation from a Rigaku X-ray generator (Rota-Flex RU200B) equipped with a confocal mirror. X-Ray diffraction (XRD) patterns were recorded in transmission geometry using an imaging plate system at a camera length of $95 \mathrm{~mm}$. Tensile properties of fibers were measured at a stretching speed of $10 \mathrm{~mm} / \mathrm{min}$ with a TENSILON universal tester $1225 \mathrm{~A}$ supplied by ORIENTEC Co., LTD.

\section{Polymerization of Poly $\left(3,3^{\prime}\right.$-dihydroxybenzidine terephthal- amide) (DHBTA)}

To a solution of $30 \mathrm{~g}$ calcium chloride and $18.8 \mathrm{~g} 3,3^{\prime}$ dihydroxybenzidine in $560 \mathrm{~mL}$ of NMP, $17.6 \mathrm{~g}$ terephtaloyl chloride was added. After the reaction mixture was stirred at $0{ }^{\circ} \mathrm{C}$ for $1 \mathrm{~h}$ and at $50^{\circ} \mathrm{C}$ for $2 \mathrm{~h}$, it was poured into a large amount of deionized water. The precipitated polymer was isolated by filtration and dried at $120^{\circ} \mathrm{C}$ for $12 \mathrm{~h}$ in a vacuum oven. The polyhydroxyamide had an inherent viscosity $\left(\eta_{\text {inh }}\right)$ of $5.73 \mathrm{dl} / \mathrm{g}$. IR $\left(\mathrm{KBr}, \mathrm{cm}^{-1}\right): 3418,3292,3058,1648,1604$, 1527, 1506, 1413, 1330, 1249, 1118, 1016, 962, 894, 866, 809, 719.

Preparation of 15 wt \% Liquid Crystalline Aqueous Solution of DHBTA in $1.03 \mathrm{~mol} / \mathrm{L}$ of Aqueous Tetramethylammonium Hydroxide Solution

In a flask $15 \mathrm{~g}$ of DHBTA was charged with a mechanical stirrer made of stainless steel. To the flask, $85 \mathrm{~g}$ of $1.03 \mathrm{~mol} / \mathrm{L}$ of aqueous tetramethylammonium hydroxide solution was added and mixed at room temperature for $5 \mathrm{~h}$. The resulting solution showed optical anisotropy under crossed Nicols through a microscope.

\section{Spinning and Heat Treatment of DHBTA Fiber}

The aqueous DHBTA solution was transferred to a cylinder. The solution was ejected at $1 \mathrm{~m} / \mathrm{min}$ through a thin metal monohole spinneret having a diameter of $150 \mu \mathrm{m}$, using a machine-operated syringe. The ejected solution was drawn in an air gap with a length of $1 \mathrm{~cm}$ between the spinneret and coagulation bath. It was drawn by the action of taking up speed at $6.4 \mathrm{~m} / \mathrm{min}$, and the solution, drawn 6.4 times, was coagulated to form a fiber in $1.5 \mathrm{~mol} / \mathrm{L}$ of aqueous $\mathrm{HCl}$ solution. After coagulation, the fiber was taken up on a bobbin and washed on the bobbin. Subsequently it was dried at $80^{\circ} \mathrm{C}$. The obtained DHBTA fiber had a linear density of 6.0 dtex. Finally, to obtain biPBO fiber, the DHBTA fiber was wound on a rigid metal frame and heated at temperatures up to $500^{\circ} \mathrm{C}$ for times up to $10 \mathrm{~min}$.

\section{RESULTS AND DISCUSSION}

\section{Polymerization of DHBTA and Dissolution Behavior in Basic Aqueous Solutions}

The precursor polymer poly (3,3'-dihydroxybenzidine terephthalamide) (DHBTA) was prepared by polycondensation of terephtaloyl chloride and 3,3'-dihydroxybenzidine in NMP, in the presence of calcium chloride, as shown in Scheme 1. The polymer was obtained by pouring the reaction solution into an excess amount of water to remove the hydrochloric acid produced during the reaction together with the solvent and the inorganic salt. Although a fiber can be produced from the isotropic reaction mixture via a wet spinning process, it is difficult to produce a fiber with good mechanical properties under these conditions. In such a wet spinning process the polymer chains will be disoriented due to fast relaxation times of the polymer chains in the isotropic solution.

The dissolution behavior of the precursor polymer DHBTA was examined in various aqueous solutions at high concentrations in order to prepare a lyotropic liquid crystalline solution. The hydroxy groups of DHBTA can be converted to phenoxide groups by the action of various bases, as shown in Scheme 2. These phenoxy groups can make the polymer soluble in aqueous solutions. Table I shows the results of the solubility behavior of DHBTA in basic aqueous solutions. It was found that the polymer dissolves in aqueous sodium 
Table I. Solubility of DHBTA in basic aqueous solutions

\begin{tabular}{|c|c|c|c|c|}
\hline $\begin{array}{l}\text { Polymer } \\
\text { Contents } \\
\text { (wt \%) }\end{array}$ & Base & $\begin{array}{c}\text { Concentration } \\
\text { of base } \\
(\mathrm{mol} / \mathrm{L})\end{array}$ & Solubility* & $\begin{array}{c}\text { Liquid** } \\
\text { Crystallinity }\end{array}$ \\
\hline 1.5 & $\mathrm{LiOH}$ & 1.0 & + & - \\
\hline 3 & $\mathrm{NaOH}$ & 2.0 & + & - \\
\hline 15 & $\mathrm{NaOH}$ & 1.5 & + & + \\
\hline 3 & $\mathrm{KOH}$ & 2.0 & + & - \\
\hline 15 & $\mathrm{KOH}$ & 1.5 & + & + \\
\hline 3 & $\mathrm{CsOH}$ & 1.5 & - & \\
\hline 3 & Pyridine & 2.0 & - & \\
\hline 3 & $\mathrm{NH}_{3}$ & 2.0 & - & \\
\hline 3 & Tetramethylammonium hydroxide & 2.0 & + & - \\
\hline 15 & Tetramethylammonium hydroxide & 1.5 & + & + \\
\hline
\end{tabular}

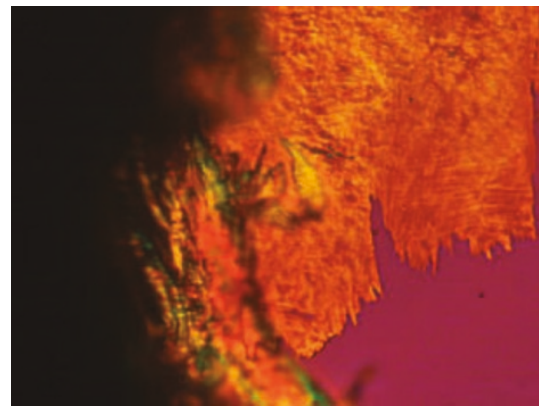

Figure 1. Polarisation microscopic image of the liquid crystalline phase of a $15 \mathrm{wt} \%$ aqueous solution of DHBTA in $1.5 \mathrm{M} \mathrm{TMAH}$ at $70^{\circ} \mathrm{C}$.
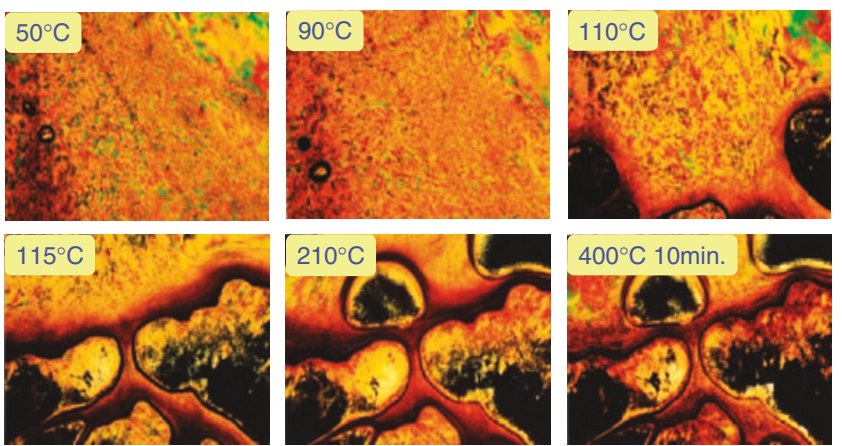

Figure 2. Polarisation microscopic image of a $10 \mathrm{wt} \%$ solution of DHBTA in $1 \mathrm{M} \mathrm{NaOH}$ at various temperatures.

hydroxide and tetramethylammonium hydroxide (TMAH) solutions at concentrations of $15 \mathrm{wt} \%$, whereas the solubility in NMP was not so high. The appearance of the aqueous solutions was that of a light brown colored paste. Figure 1 shows the microscopic image of a $15 \mathrm{wt} \%$ aqueous solution of DHBTA in 1.5 M TMAH at $70{ }^{\circ} \mathrm{C}$. The observed birefringence shows that the sample is liquid crystalline. Figure 2 shows the microscopic image of a $10 \mathrm{wt} \%$ aqueous solution of DHBTA in $1.0 \mathrm{M} \mathrm{NaOH}$ at various temperatures. The clearing temperature was found to be higher than the boiling point of water. After evaporation of the water the polymer salt was stable up to $450{ }^{\circ} \mathrm{C}$.
Table II. Degradation behavior of DHBTA in basic aqueous solvents at $85^{\circ} \mathrm{C}$

\begin{tabular}{ccc}
\hline $\begin{array}{c}\text { Time } \\
(\min )\end{array}$ & $\begin{array}{c}\text { Inherent viscosity of TMAH } \\
\text { aqueous solution } \\
(\mathrm{dL} / \mathrm{g})\end{array}$ & $\begin{array}{c}\text { Inherent viscosity of } \mathrm{NaOH} \\
\text { aqueous solution } \\
(\mathrm{dL} / \mathrm{g})\end{array}$ \\
\hline 10 & 5.1 & 3.6 \\
30 & 4.8 & 2.1 \\
45 & 4.1 & 1.6 \\
\hline
\end{tabular}

a) DHBTA solution (15 wt \%) was heated for the indicated time

\section{Stability of Aqueous Solution}

Because aromatic polyamides are known to be easily hydrolyzed under basic conditions, it is important to check the stability of the aqueous solutions of the DHBTA polymer. Table II shows the inherent viscosity changes of the polymer solutions in which the liquid crystalline solutions were stirred at $85^{\circ} \mathrm{C}$ for the times indicated in the Table II. The results show that DHBTA in aqueous sodium hydroxide solution is hydrolyzed considerably in $30 \mathrm{~min}$. The DHBTA polymer in aqueous TMAH solution is less susceptible towards degradation. It is concluded that the TMAH solution is still suitable for fiber spinning after $45 \mathrm{~min}$ aging at $85^{\circ} \mathrm{C}$.

\section{Tensile Properties of DHBTA Fiber}

DHBTA fiber was successfully spun from the liquid crystalline aqueous TMAH solution via a wet spinning process. The fiber shows excellent drawability. In order to achieve higher orientation the ejected polymer solution was stretched several times between the spinneret and coagulation bath (see drawing ratio in Table III), controlled by the taking up speed. In the present case, an aqueous hydrochloric acid solution was used both for coagulation of the precursor polymer and for neutralization of the base that is contained in the fiber after leaving the spinneret. As shown in Table III, DHBTA fiber spun from a $20 \mathrm{wt} \%$ liquid crystalline TMAH solution has a seven times higher modulus than a yarn spun from an isotropic NMP solution. In this experiment the drawing ratio was as high as 28.8. A fiber spun from aqueous $\mathrm{NaOH}$ solution, however, showed poor properties even though the spinning solution was 
Table III. Properties of DHBTA fiber spun from various spinning solutions

\begin{tabular}{|c|c|c|c|c|c|c|c|}
\hline Solvent & $\begin{array}{l}\text { State of } \\
\text { polymer } \\
\text { solution }\end{array}$ & $\begin{array}{c}\text { Polymer } \\
\text { concentration } \\
\text { (wt \%) }\end{array}$ & $\begin{array}{c}\text { Drawing } \\
\text { ratio }^{\text {a) }} \\
\text { (times) }\end{array}$ & $\begin{array}{l}\text { Tenacity } \\
(\mathrm{mN} / \text { tex })\end{array}$ & $\begin{array}{c}\text { Elongation } \\
\text { at break } \\
(\%)\end{array}$ & $\begin{array}{l}\text { Modulus } \\
\text { (GPa) }\end{array}$ & $\begin{array}{c}\text { Orientation } \\
\text { Parameter } \\
\text { (F) }\end{array}$ \\
\hline $\begin{array}{c}1.03 \mathrm{~mol} / \mathrm{L} \text { of } \\
\mathrm{TMAH} \mathrm{aq}\end{array}$ & $\begin{array}{l}\text { Liquid } \\
\text { crystal }\end{array}$ & 15 & 3.2 & 1141 & 7.4 & 50 & 0.85 \\
\hline $\begin{array}{c}1.03 \mathrm{~mol} / \mathrm{L} \text { of } \\
\mathrm{TMAH} \text { aq }\end{array}$ & $\begin{array}{l}\text { Liquid } \\
\text { crystal }\end{array}$ & 15 & 6.4 & 930 & 7.5 & 48 & - \\
\hline $\begin{array}{c}1.03 \mathrm{~mol} / \mathrm{L} \text { of } \\
\mathrm{TMAH} \text { aq }\end{array}$ & $\begin{array}{l}\text { Liquid } \\
\text { crystal }\end{array}$ & 20 & 28.8 & 1347 & 4.5 & 75 & - \\
\hline $\begin{array}{c}1.5 \mathrm{~mol} / \mathrm{L} \mathrm{of} \\
\mathrm{NaOH} \text { aq }\end{array}$ & $\begin{array}{l}\text { Liquid } \\
\text { crystal }\end{array}$ & 15 & - & 239 & 11.4 & 14 & 0.42 \\
\hline $\mathrm{NMP} / \mathrm{CaCl}_{2}$ & Isotropic & 8 & 1 & 300 & 60 & 11 & 0.53 \\
\hline
\end{tabular}

a) Drawing ratio $=$ (taking up speed of fiber) $/($ extrusion speed of polymer solution)

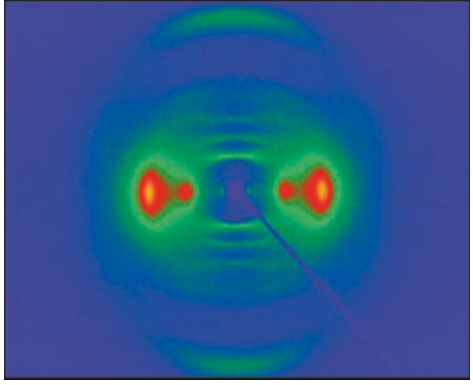

(a)

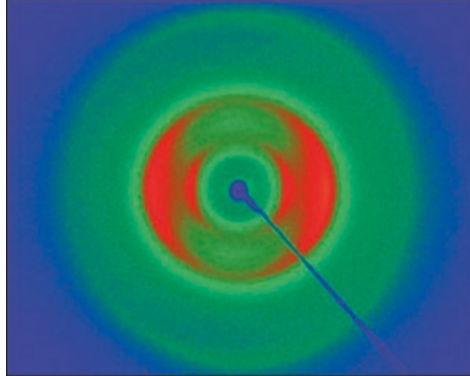

(b)

Figure 3. Flat plate XRD pattern of DHBTA fiber from (a) liquid crystalline solution (15 wt \% DHBTA in $1.03 \mathrm{~mol} / \mathrm{IMAH}$ ) and (b) isotropic solution (DHBTA in $\mathrm{NMP} / \mathrm{CaCl}_{2}$ ).

liquid crystalline. Clearly this is due to degradation of the polymer, as was discussed above.

\section{Orientation of DHBTA Fiber}

The difference in structural characteristics between a fiber spun from a liquid crystalline aqueous TMAH solution and a fiber spun from an isotropic $\mathrm{NMP} / \mathrm{CaCl}_{2}$ solution can be clearly observed by XRD analysis, as can be seen in Figure 3.

In particular XRD allows a quantitative determination of the orientation of the polymer chains with respect to the fiber axis. The Hermans orientation factor $\mathrm{F}$ is a convenient measure of this orientation. It is given by

$$
\begin{aligned}
& \left\langle\cos ^{2} \phi\right\rangle=\frac{\int_{0}^{\pi / 2} I(\phi) \cos ^{2} \phi \sin \phi d \phi}{\int_{0}^{\pi / 2} I(\phi) \sin \phi d \phi} \\
& F=\frac{3\left\langle\cos ^{2} \phi\right\rangle-1}{2}
\end{aligned}
$$

Here $\phi$ is an azimuthal angle in the two-dimensional XRD pattern of the fiber and $I(\phi)$ is the azimuthal intensity profile extracted from the two-dimensional XRD pattern.

The Hermans orientation parameter of the DHBTA fiber spun from a liquid crystalline aqueous TMAH solution is over 0.8 (Table III). This is much higher than that of the DHBTA fiber spun from an isotropic solution of DHBTA in NMP/ $\mathrm{CaCl}_{2}$, which has an orientation parameter of 0.5 . Since the viscosity of a liquid crystalline solution becomes very low by shear in the spinneret, due to partial orientation of the liquid crystalline domains, the ejected polymer solution can be easily stretched in the air gap. This stretching process in the air gap aligns the directors of the liquid crystalline domains because the polymer chains in a liquid crystalline solution have much longer relaxation times than those in an isotropic solution. It was difficult to stretch the isotropic solution because of the poor spinnability of the solution. As Table III shows, these points lead to a higher orientation of the polymer chains in the precursor fiber spun from a liquid crystalline aqueous TMAH solution than the fiber spun from an isotropic solution. The higher orientation translates into a higher modulus and strength.

\section{Study of the Ring Closure Reaction of DHBTA Fiber}

The DHBTA fiber was heated in order to achieve a solid state transition from the hydroxylamide structure into the azole type structure of the biPBO fiber via the ring closure reaction shown in Scheme 3. Figure 4 shows IR spectra of DHBTA powder before and after heat treatment. After heat treatment at $500{ }^{\circ} \mathrm{C}$ for $10 \mathrm{~min}$, the peak between 3600 and $3100 \mathrm{~cm}^{-1}$ due to $\mathrm{OH}$ and $\mathrm{NH}$ vibrations decreased considerably. Furthermore, the peak at $1648 \mathrm{~cm}^{-1}$ due to the $\mathrm{C}=\mathrm{O}$ stretch vibration disappeared, and a peak at $1060 \mathrm{~cm}^{-1}$ due to C-O-C stretch vibration was observed. These results indicate that the hydroxylamide structure is transformed into the biPBO structure as a result of the heat treatment. 


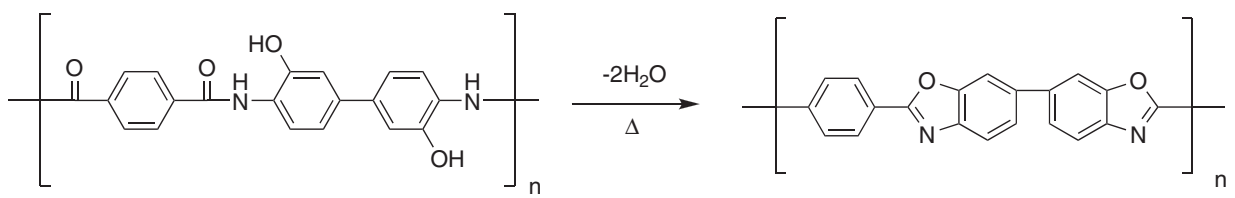

Scheme 3. Transformation of DHBTA to biPBO via a ring closure reaction at elevated temperature.

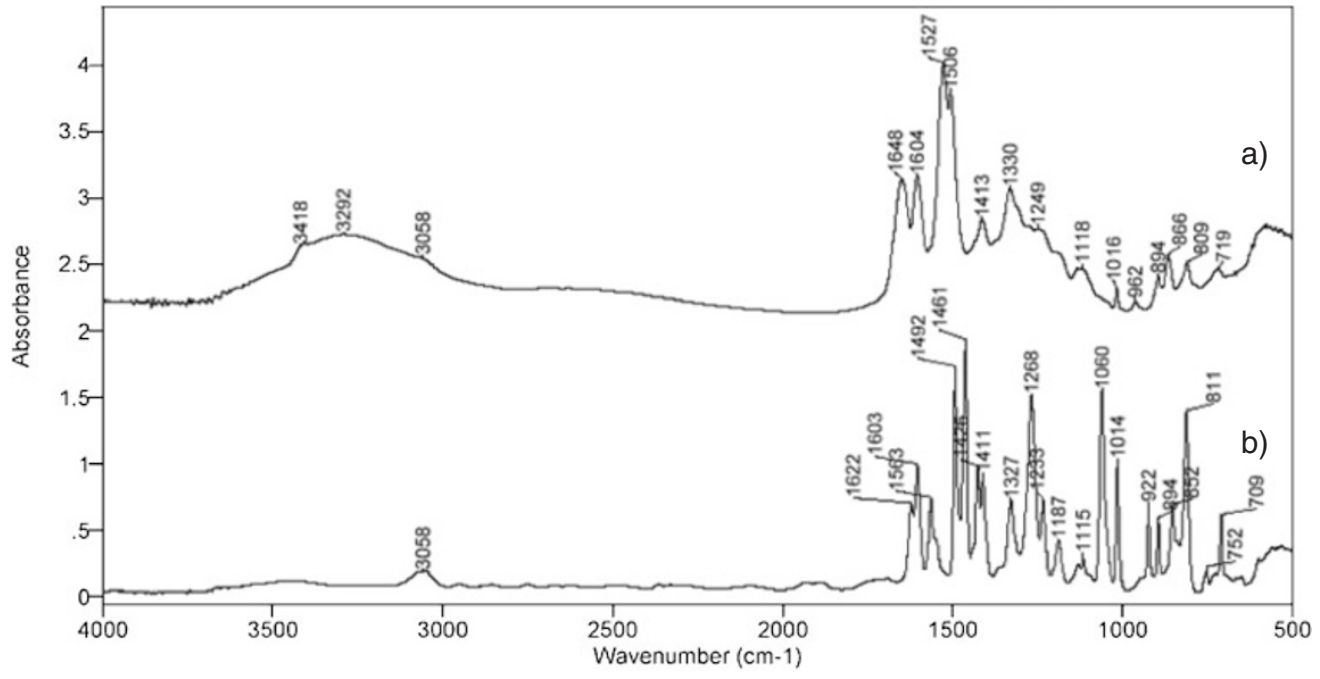

Figure 4. IR spectra of DHBTA powder: (a) before, and (b) after heat treatment.

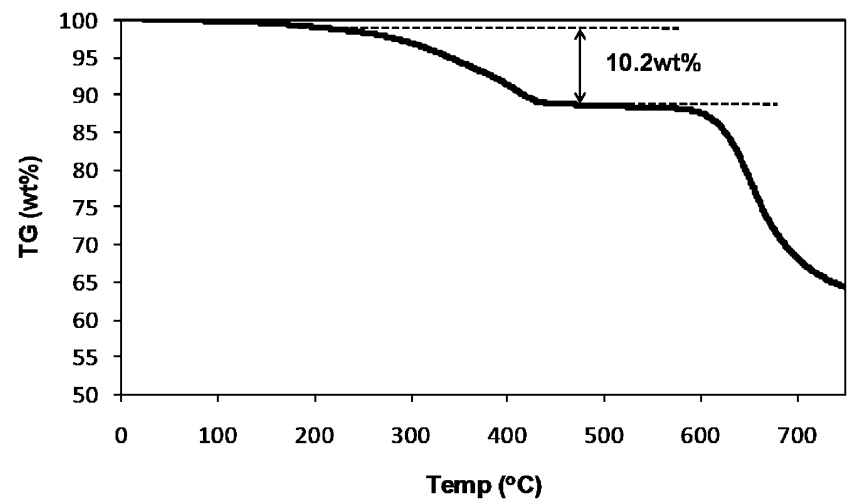

Figure 5. TGA diagram of DHBTA powder that was dried for $30 \mathrm{~min}$ at $100^{\circ} \mathrm{C}$ to remove residual solvent.

Figure 5 shows a TGA diagram of DHBTA powder that was dried for $30 \mathrm{~min}$ at $100^{\circ} \mathrm{C}$. If ring closure has occurred according to Scheme 3, the calculated weight loss due to the loss of water molecules must be $10.5 \%$. The TGA curve shows a weight loss of $10.2 \%$ in the temperature range from $200^{\circ} \mathrm{C}$ to about $450{ }^{\circ} \mathrm{C}$. This suggests that the degree of ring closure is likely to be very close to $100 \%$. According to the TGA diagram the onset of thermal degradation of the formed biPBO polymer lies above $600^{\circ} \mathrm{C}$.

The ring closure reaction leads to a marked shortening of the biPBO polymer chain as compared to the hydroxylamide polymer chain. By measuring the spacings of the peaks in the meridional X-ray diffraction patterns of both the precursor yarn and the biPBO yarn it was found that the length of the repeat unit of the precursor polymer is $1.72 \mathrm{~nm}$, whereas that of the biPBO polymer is only $1.58 \mathrm{~nm}$. This implies that the fiber shrinks upon heat treatment by $8.0 \%$ as a result of the ring closure reaction. Further analysis of the precursor polymer and the heat-treated polymer by means of XRD will be reported in a separate paper.

\section{Tensile Properties of biPBO Fiber}

The precursor polymer fiber DHBTA was subjected to various heat treatments with temperatures up to $500{ }^{\circ} \mathrm{C}$, as can be seen in Table IV. It is observed that the biPBO fibers have a higher modulus as compared to their DHBTA precursor fibers. The highest modulus values were obtained for a precursor polymer spun from a $20 \mathrm{wt} \%$ liquid crystalline aqueous TMAH solution and a biPBO polymer that was ring-closed at $450^{\circ} \mathrm{C}$ for $10 \mathrm{~min}$ under controlled tensioning. The biPBO polymer obtained from the precursor that was spun from a spinning solution with $15 \mathrm{wt} \%$ polymer concentration has a higher orientation than its precursor polymer. Therefore part of the observed modulus increase upon heat treatment may be due to the observed higher orientation of the biPBO fiber, as is clear from the relation between the tensile modulus and the chain orientation as reported by Northolt et al. ${ }^{12}$

Energy calculations can be employed to calculate the chain modulus of a polymer, i.e., the limiting elastic modulus along the polymer chain axis. This approach is based on Hooke's law, which is given by 
Table IV. Properties of biPBO fibers obtained by heat treatment from their DHBTA precursor fibers

\begin{tabular}{|c|c|c|c|c|c|c|c|}
\hline & $\begin{array}{c}\text { Temperature } \\
\left({ }^{\circ} \mathrm{C}\right)\end{array}$ & $\begin{array}{l}\text { Time } \\
(\min )\end{array}$ & $\begin{array}{l}\text { Tension } \\
\text { in heat } \\
\text { treatment } \\
\text { (cN/dtex) }\end{array}$ & $\begin{array}{l}\text { Tenacity } \\
(\mathrm{mN} / \text { tex })\end{array}$ & $\begin{array}{c}\text { Elongation } \\
\text { at break } \\
(\%)\end{array}$ & $\begin{array}{l}\text { Modulus } \\
\text { (GPa) }\end{array}$ & $\begin{array}{c}\text { Orientation } \\
\text { parameter } \\
(\mathrm{F})\end{array}$ \\
\hline DHBTA $^{\text {a) }}$ & - & - & - & 1141 & 7.4 & 50 & 0.85 \\
\hline biPBOa) & 400 & 7.5 & - & 923 & 2.4 & 64 & 0.96 \\
\hline biPBOa) & 450 & 7.5 & - & 925 & 2.5 & 62 & 0.97 \\
\hline DHBTA $^{\text {b) }}$ & - & - & - & 1347 & 4.5 & 75 & \\
\hline biPBO $^{b)}$ & 450 & 10 & 1.0 & 911 & 1.4 & 95 & \\
\hline biPBO $^{b}$ & 450 & 10 & 1.5 & 868 & 1.3 & 100 & \\
\hline DHBTA $^{c)}$ & - & - & - & 300 & 60 & 11 & \\
\hline biPBOc) & 500 & 10 & - & 265 & 9.8 & 13 & \\
\hline
\end{tabular}

a) DHBTA precursor spun from liquid crystalline aqueous TMAH solution with $15 \mathrm{wt} \%$ pol. conc. b) DHBTA precursor spun from liquid crystalline aqueous TMAH solution with $20 \mathrm{wt} \%$ pol. conc. ${ }^{\mathrm{c}}$ DHBTA precursor spun from isotropic $\mathrm{NMP} / \mathrm{CaCl}_{2}$ solution

Table V. Calculated chain modulus of DHBTA and biPBO based on semi-empirical energy calculations using the program WINMOPAC

\begin{tabular}{ccc}
\hline & DHBTA & biPBO \\
\hline Hamiltonian & AM1 & AM1 \\
Unit length $(\mathrm{nm})$ & 1.73 & 1.58 \\
Chain modulus $(\mathrm{GPa})$ & 255 & 340 \\
\hline
\end{tabular}

$$
\begin{aligned}
& E=1 / 2 k x^{2} \\
& \frac{d E}{d x}=k x
\end{aligned}
$$

Here $E$ is the potential energy of a repeat unit of the polymer, $x$ is the strain applied to the repeat unit and the factor $k$ corresponds to the modulus. Using this approach the potential energy of a repeat unit of the polymer is calculated as function of the applied strain. ${ }^{13,14}$ This approach was employed to calculate the chain modulus of DHBTA and biPBO using the WINMOPAC software package. The results are shown in Table V. The observed larger rigidity of the biPBO fibers is supported by the energy calculations, since the calculated chain modulus of biPBO is significantly higher than that of DHBTA. Although much improvement still has to be done for the optimization of the spinning process, these calculations show high potential of the biPBO fiber.

\section{CONCLUSIONS}

In this report we describe a new lyotropic aqueous solution of the tetramethyl ammonium salt of the polymer poly(3,3'dihydroxybenzidine terephthalamide). This solution shows excellent properties in terms of formability and spinnability.
The solution can be formed into a polyhydroxyamide fiber by an air gap wet spinning process. The resulting fiber has higher orientation and better mechanical properties than a polyhydroxyamide fiber spun from an isotropic solution. The polyhydroxyamide fiber was converted successfully into a biPBO fiber by a heat treatment process. The novel process allows the spinning of a bisoxazole fiber with promising mechanical properties without using corrosive sulfuric acid, phosphoric acid or organic solvents.

Received: March 18, 2009

Accepted: May 11, 2009

Published: June 24, 2009

\section{REFERENCES}

1. S. L. Kwolek, U. S. Patent 2671542 (1972).

2. S. L. Kwolek, U. S. Patent 3819587 (1974).

3. H. Blades and D. Hockessin, U.S. Patent 3767756 (1973).

4. H. Blades and D. Hockessin, U.S. Patent 3869429 (1975).

5. Y. Imai, I. Taoka, K. Uno, and Y. Iwakura, Macromol. Chem., 83, 167 (1965).

6. T. Gregory, C. W. Hurtig, H. D. Ledbetter, K. J. Quackenbush, and S. Rosenberg, U.S. Patent 5219981 (1993).

7. T. Kitagawa, H. Murase, and K. Yabuki, J. Polym. Sci., Part B: Polym. Phys., 36, 39 (1998).

8. T. Kitagawa, T. Ishitobi, and K. Yabuki, J. Polym. Sci., Part B: Polym. Phys., 38, 1605 (2000).

9. F. N. Smith and H. Van Droffelaar, Br. Corros. J., 26, 265 (1991).

10. T. Kubota and R. Nakanishi, J. Polym. Sci., Polym. Lett. Ed., 2, 655 (1964).

11. S. W. Kantor and J. Sonnenberg, G.B. Patent 1142071 (1969).

12. M. G. Northolt and R. v. d. Hout, Polymer, 26, 310 (1985).

13. M. J. S. Dewar, E. G. Zoebisch, E. F. Healy, and J. J. P. Stewart, J. Am. Chem. Soc., 107, 3902 (1985).

14. F. Pichierri and A. Sarai, Chem. Phys. Lett., 322, 536 (2000). 